\title{
Prosthodontic Need among Adults of Hubli, Karnataka India
}

\author{
R. Kalyanpur1 , U.R. Bilagi², P.J. Shetty³ \\ ${ }^{1}$ Department of Public Health Dentistry, SDM College of Dental Sciences and Hospital, Dharwad, Karnataka, India. \\ ${ }^{2}$ Department of Cardiology, KIMS, Hubli, Karnataka, India. ${ }^{3}$ Department of Public Health Dentistry, SDM College of \\ Dental Sciences and Hospital, Dharwad, Karnataka, India.
}

\section{ABSTRACT}

\section{BACKGROUND}

Prosthodontic needs are the determinants of tooth rehabilitation as tooth replacement is important to restore the vital functions of the teeth like mastication, aesthetics, phonetics etc., finally contributing to better quality of life. Estimating the prosthodontic needs is essential for planning prosthodontic service for the given population. Thus, the present study aims to assess the prosthodontic needs among the adults of Hubli city and to know its association with the selected sociodemographic parameters like age, gender, educational level, occupation and diet.

\section{METHODS}

A total of 685 adult subjects was included for the study. House to house survey was conducted and information on prosthodontic needs and sociodemographic variables were gathered by interview and clinical examination method. Collected data was analysed by descriptive statistics and chi-square test.

\section{RESULTS}

Out of 685 subjects, $56.3 \%$ are males and $43.6 \%$ are females. $44.8 \%$ required prosthetic teeth among which $31.3 \%$ needed upper arch teeth and $36 \%$ were in need of lower teeth. Prosthetic needs were more among females (50.1\%), 59-65 years old $(88.5 \%)$, with primary education (56.9\%), married people $(49.1 \%)$, Hindus (45.8\%), farmers (68.4\%) and among vegetarians (47.7\%). Chi-square results showed that, prosthodontic needs are significantly associated with sex $(\mathrm{p}=$ $.013)$, age $(\mathrm{p}=.000)$, marital status $(\mathrm{p}=.000)$ and occupation $(\mathrm{p}=.000)$.

\section{CONCLUSIONS}

Prosthodontic needs are more among the adults of Hubli region indicating a negative attitude towards tooth retention. Hence, public should be made aware of maintaining healthy teeth and preventing the teeth loss. Further, people of Hubli area should be encouraged to get the teeth replacement at the earliest. Also, there is a need to implement affordable and accessible prosthodontic care for this population as nearly half of the adults need teeth prosthesis.

\section{KEY WORDS}

Prosthodontic Need, Tooth Loss, Oral Health
Corresponding Author:

Dr. Ramya Kalyanpur,

Assistant Professor,

Department of Public Health Dentistry,

SDM College of Dental Sciences and

Hospital, Dharwad, Karnataka, India.

E-mail: ramyakalyanpur@gmail.com

DOI: $10.14260 /$ jemds/2019/733

Financial or Other Competing Interests: None.

How to Cite This Article:

Kalyanpur $R$, Bilagi UR, Shetty PJ. Prosthodontic need among adults of Hubli, Karnataka India. J. Evolution Med. Dent. Sci. 2019;8(45):3378-3381, DOI: $10.14260 /$ jemds $/ 2019 / 733$

Submission 27-07-2019,

Peer Review 24-10-2019,

Acceptance 30-10-2019,

Published 11-11-2019. 


\section{BACKGROUND}

Prosthodontic needs are the direct indictors of total amount of edentulous space seen in the dental arches due to missing teeth in the oral cavity. They are also an indirect estimate of burden of untreated oral diseases and individuals' attitude towards oral health as the prosthodontic needs urge for tertiary mode of intervention. ${ }^{1}$ These needs are assessed by counting the number of missing teeth in both the jaws. Such prosthetic needs demand for teeth replacement either fixed or removable in nature or partial or complete. ${ }^{1}$ However, the impact of these prosthetic needs differs noticeably from anterior and posterior region of the mouth. This is mainly due to the fact that, individuals tend to seek for early tooth rehabilitation for anterior teeth than the posterior teeth as they are more concerned about their aesthetic and social performance. ${ }^{2,3}$

Thus, estimating prosthodontic needs are the guiding channels for tooth rehabilitation because artificial teeth can aid in recovery of the functions of teeth like mastication, aesthetics, phonetics and self-defence. ${ }^{4,5}$ But, if these needs are left uncorrected then it can lead to tooth dysfunctions like aesthetic and masticatory impairment, drifting of teeth, social inferiority, compromised nutrition and ultimately a diminished quality of life. Prosthodontic needs also vary with socio demographic parameter like age, sex, income, religion etc as the individual's preferences for oral care are influenced by these social variables. ${ }^{6}$ In fast developing and diverse country like India, individuals show a profound retrograde negligent attitude towards oral health as compared to general health. ${ }^{7}$ This is mainly due to the nature of the oral diseases which are not life threatening but contributing for prosthodontic need if untreated. 8 Further, prosthodontic needs do vary from one geographic region to the other due the polymorphic nature of Indian population.

From the government perspective, lot of importance is given for medical services including rehabilitation care than the dental facility thus, paving the way for imbalanced health care delivery in India. ${ }^{9,10}$ Similar pattern of health service imbalance is observed in the Hubli city of Karnataka where the dental care is rendered by few dental clinics and meagre government linked oral health care. This inadequacy of service may not cover the entire Hubli population who need the prosthodontic replacement. Also, there is paucity of data on the prosthodontic needs in the Hubli city. Gathering such data can be a baseline source of information for planning appropriate teeth rehabilitative care for this population.

We wanted to determine the prosthodontic needs among the adults of Hubli region and its association with selected socio demographic variables.

\section{METHODS}

\section{Study Area and Sample Size}

This cross-sectional survey was conducted in the Hubli city, which is one of the talukas under Dharwad district, Karnataka, India. As per the population census report 2011, total population of Hubli is 943,788 . To determine the sample size a pilot study was conducted among the randomly chosen adults of Hubli. Based on the results of pilot study the estimated prevalence of prosthodontic needs was 30\% and the level of significance was set at $5 \%$. Using this, the sample size was determined to be 685 .

$$
n=\frac{Z^{2} P Q N}{(N-1) e^{2}+Z^{2} P Q}
$$

$\mathrm{Z}=$ Standard normal at $5 \%$ level of significance or $95 \%$ confidence level (1.96)

$\mathrm{P}=$ Sample proportion

$\mathrm{Q}=$ Alternative proportion $(1-\mathrm{P})$

$\mathrm{N}=$ Target population size (9 lakhs)

$\mathrm{e}=$ Acceptable error $(2 \%)$

\section{Inclusion Criteria}

1. Subjects who are between the age of 18-65 years.

2. Subjects willingness to participate in the study.

3. Subjects should be residents of Hubli for at least past 5 years.

\section{Exclusion criteria}

1. Subjects who are unwilling to participate.

2. Subjects who are physically and mentally challenged.

3. Subjects who do not satisfy the criteria of residents of Hubli.

4. Third molars were excluded.

\section{Method of Collection of Data}

Prior to start of this survey, ethical clearance was obtained from the SDM college of dental sciences and hospital, Dharwad. Further an official permission to do the survey was taken from the concerned authorities of Hubli city. A door to door survey was conducted and included only those subjects who met all the inclusion criteria. All these subjects were chosen by convenient sampling method till the desired sample size is achieved. Information pertaining to the aim of the study was obtained by interview and clinical examination method. All the relevant data was recorded in a self-designed proforma which was divided into two parts. Part 1 of the proforma consisted of selected demographic variables like age, sex, occupation, education, religion and diet and part 2 on prosthodontic needs. Face to face interview was done to gather the demographic data. Followed which, prosthodontic needs were assessed by counting the total number of missing teeth by clinical examination method. These needs were coded as: "one unit" which imply only one teeth replacement is required; "multi-unit" where more than one tooth needs to be replaced and "Full unit "denotes full arch replacement. Proper infection control measures were followed for oral examination and nearly 30 subjects were interviewed and examined per day. It took about 15 minutes per subject on most of the occasions. This procedure was continued till the desired sample size of 685 was achieved.

\section{Statistical Analysis}

The data was statistically analysed with descriptive statistics and chi-square test using statistical software SPSS 20.0 version. Results were considered to be statistically significant only if the $p$ value was less than 0.05 . 


\section{RESULTS}

Out of 685 subjects, $56.3 \%$ were males and $43.6 \%$ were females. Greater number of subjects belonged to the age group of $18-28$ years $(n=276,40.2 \%)$ and least were in the age group of 59-65 years $(n=61,8.91 \%)$. (Table 1$)$. A total of $44.8 \%$ of the adult subjects were in need of dental prosthesis (Table 2). Among which 31.3\% needed upper arch prosthesis and $36 \%$ were in need of lower arch prosthesis. Further in the upper arch, $30.2 \%$ needed one or multi-unit prosthesis and $1.17 \%$ required full arch prosthesis. Similarly, in the lower arch, $35.3 \%$ were in need of one or multi-unit prosthesis and $1 \%$ needs full unit prosthesis. (Table 3)

Chi-square results shows that, prosthodontic needs were significantly associated with sex which means, females have more needs than males ( $\%=50.1 ; \mathrm{p}=.013)$.Likewise subjects between $58-65$ years had higher needs $(\%=88.5 ; p=.000)$ as compared to other age groups. Prosthetic needs were also greater among married subjects $(\%=49.1 ; \mathrm{p}=.000)$ than unmarried subjects. Also, these needs were significantly associated with the occupation of the subjects being higher among the people doing agriculture $(\%=68.4 ; p=.000)$ as related to other occupation groups. Other variables like religion, education level and type of diet had no association with prosthodontic needs (Table 3).

\begin{tabular}{|c|c|c|}
\hline Variable & $\mathbf{n}$ & $\mathbf{\%}$ \\
\hline \multicolumn{3}{|c|}{ Age Group (in Years) } \\
\hline $18-28$ & 276 & 40.29 \\
\hline $28-38$ & 180 & 26.28 \\
\hline $39-48$ & 98 & 14.31 \\
\hline $49-58$ & 70 & 10.22 \\
\hline $59-65$ & 61 & 8.91 \\
\hline \multicolumn{3}{|c|}{ Sex } \\
\hline Male & 386 & 56.3 \\
\hline Female & 299 & 43.6 \\
\hline Table 1. Age and Sex Wise Distribution of Study Subjects \\
\hline
\end{tabular}

\begin{tabular}{|c|c|c|}
\hline Total Prosthodontic Need & $\mathbf{n}$ & $\%$ \\
\hline No Prosthesis & 378 & 55.18 \\
\hline Prosthetic Need & 307 & 44.82 \\
\hline Total & 685 & 100.0 \\
\hline \multicolumn{3}{|c|}{ Table 2. Prosthodontic Needs among Adults of Hubli } \\
\hline
\end{tabular}

\begin{tabular}{|c|c|c|}
\hline Dental Arch & n & \% \\
\hline \multicolumn{2}{|c|}{ Upper Arch Need } \\
\hline No Prosthesis & 478 & 69.78 \\
\hline One Unit and Multi-unit & 207 & 30.2 \\
\hline Full Prosthesis & 8 & 1.17 \\
\hline No Prosthesis & 445 & 64.96 \\
\hline One Unit and Multi-unit & 240 & 35.3 \\
\hline Full Prosthesis & 7 & 1 \\
\hline Table 3. Arch Wise Distribution of Prosthodontic Needs \\
among Adults of Hubli \\
\hline
\end{tabular}

\begin{tabular}{|c|c|c|c|}
\hline \multirow[b]{2}{*}{ Variables } & \multicolumn{2}{|c|}{ Prosthetic Need } & Chi Square $\left(\chi^{2}\right)$ \\
\hline & No Prosthesis & $\begin{array}{c}\text { Prosthetic } \\
\text { Need }\end{array}$ & \multirow{4}{*}{$\chi^{2=}=6.14, \mathrm{df}=1 ; \mathrm{p}=.013$} \\
\hline \multicolumn{3}{|c|}{ Sex } & \\
\hline Male & $229(59.3)$ & $157(40.67)$ & \\
\hline Female & $149(49.8)$ & $150(50.1)$ & \\
\hline \multicolumn{3}{|c|}{ Age Group } & \multirow{6}{*}{$\chi^{2}=96.43, \mathrm{df}=4 ; \mathrm{p}=.000$} \\
\hline $18-28$ & $196(71)$ & $80(28.9)$ & \\
\hline $29-38$ & $107(59.4)$ & $73(40.5)$ & \\
\hline $39-48$ & $47(47.9)$ & $51(52)$ & \\
\hline $49-58$ & $21(30)$ & $49(70)$ & \\
\hline $58-65$ & $7(11.4)$ & $54(88.5)$ & \\
\hline \multicolumn{3}{|c|}{ Education Level } & \multirow{6}{*}{$\chi^{2}=7.11, d f=4 ; p=.13$} \\
\hline No Education & $34(51.5)$ & $32(48.4)$ & \\
\hline Primary & $25(43.1)$ & $33(56.9)$ & \\
\hline Secondary & $146(60.8)$ & 94 (39.1) & \\
\hline Graduation & $126(54)$ & $107(45.9)$ & \\
\hline Professionals & $47(53.4)$ & $41(46.5)$ & \\
\hline
\end{tabular}

\begin{tabular}{|c|c|c|c|}
\hline \multicolumn{3}{|c|}{ Marital Status } & \multirow{3}{*}{$\chi^{2=} 12.66, \mathrm{df}=1 ; \mathrm{p}=.000$} \\
\hline Married & $246(50.8)$ & 238 (49.1) & \\
\hline Unmarried & $132(65.6)$ & $69(34.3)$ & \\
\hline \multicolumn{3}{|c|}{ Religion } & \multirow{6}{*}{$\chi^{2}=7.75, d f=4 ; p=.10$} \\
\hline Hindu & 325 (54.1) & 275 (45.8) & \\
\hline Muslim & $32(56.1)$ & $25(43.8)$ & \\
\hline Christian & $.00(0)$ & $1(100)$ & \\
\hline Jain & $20(80)$ & $5(20)$ & \\
\hline Others & $1(50)$ & $1(50)$ & \\
\hline \multicolumn{3}{|c|}{ Occupation } & \multirow{6}{*}{$\chi^{2}=21.09, \mathrm{df}=4 ; \mathrm{p}=.000$} \\
\hline Agriculture & $12(31.5)$ & $26(68.4)$ & \\
\hline Business & $69(60.5)$ & $45(39.4)$ & \\
\hline Government employee & $59(50.4)$ & $58(49.5)$ & \\
\hline $\begin{array}{c}\begin{array}{c}\text { Non- government } \\
\text { employee }\end{array} \\
\end{array}$ & $112(66.2)$ & $57(33.7)$ & \\
\hline Others & $126(51)$ & $121(48.9)$ & \\
\hline \multicolumn{3}{|c|}{ Diet } & \multirow{3}{*}{$\chi^{2}=4.34, \mathrm{df}=1 ; \mathrm{p}=.11$} \\
\hline Vegetarians & $198(52.2)$ & $181(47.7)$ & \\
\hline Non - vegetarians & $180(58.8)$ & $126(41.1)$ & \\
\hline \multicolumn{4}{|c|}{$\begin{array}{c}\text { Table 4. Association Between Prosthodontic Needs and } \\
\text { Sociodemographic Variables }\end{array}$} \\
\hline
\end{tabular}

\section{DISCUSSION}

Present survey findings showed that, $44.8 \%$ of the adult subjects were in need of dental prosthesis either one-unit, multi-unit or full arch replacement. This is a striking evidence that, in Hubli people are losing their teeth at their adult age only, which is an alarming sign of oral health negligence. These findings are in accordance with the prosthetic needs among the Saudi adult subjects being $46.7 \%{ }^{6}$ But contrast findings were seen in the adults of Nalgonda region of Andhra Pradesh which is a sister state of Karnataka, where the prosthodontic needs are only $35 \% .^{11}$ This means that, there exists clear regional disparity in the prosthodontic needs and accordingly prosthodontic services has to be planned.

Further, these needs were more among the older adults between 58 - 65 years. This is similar to the findings of Myanmar adults and also among the adults of Saudi Arabia. ${ }^{12,13}$ This could be due to lack of awareness and availability of oral health services along with the higher expenses associated with the treatment of oral diseases. Collectively leading to accumulation of oral diseases resulting in need for tooth rehabilitation.

This survey results also exposed that; females were in more need for dental prosthesis than males. Such findings may be due to the dependency of the females on their male counterpart which may restrict them from seeking early oral care. Further, lack of conscious awareness regarding oral health could be one of the contributing factors. But, if proper measures are taken, then females may seek for prosthetic dental care than the males due to aesthetic reasons. However, studies conducted among the adults of Mumbai did not show any gender differences in the prosthodontic needs. ${ }^{14}$ Opposite findings are observed among the adults of North Karnataka region, where males had higher prosthodontic needs as compared to the females. ${ }^{15}$ Hence, it is required to further probe into the behavioural aspects associated with the gender and prosthodontic needs.

Current study reports that, married people were in more need for prosthodontic need than the unmarried. This could be due to increased commitments of their life which usually make them to give lower importance to oral health as they are not an emergency thus encouraging them to neglect their oral problems. Another influencing factor in this study was occupation. Subjects whose occupation is farming, had more need than subjects of other occupation. Similar findings were 
reported among the Guatemala subjects. ${ }^{16}$ This may be due to the difficulties faced by the Indian farmers in their occupational matter where finances are extremely problematic making them to lead a tougher life than other sector people. Also, there are no government linked oral health schemes for adults which is an added reason for such higher number of prosthetic needs.

Thus, our study findings highlight that, prosthodontic needs are greater among the adults of Hubli city. Which is a real concern as it a clear reflection that, people of this area are least bothered about their oral health. Further, studies in future are required to compare the prosthetic needs among the adults and geriatrics of this region and the Karnataka state as a whole. Such survey helps to plan and implement appropriate pan oral health rehabilitation programs.

\section{CONCLUSIONS}

Prosthodontic needs are more among the adults of Hubli and it is significantly associated with age, sex, marital status and occupation. Considering these factors, supporting prosthodontic rehabilitation schemes or services should be initiated and these should be affordable, accessible and available for this population. Along with this, public should be made aware of the importance of oral health and the available prosthodontic care. People should also be made to understand the significance of getting this rehabilitation at the earliest. All these should motivate the public to involve in seeking oral health care so that they can prevent having the prosthodontic needs. Success of such programs depends on good governance and is indicated by reduction in the prosthodontic needs, meaning people are concerned about tooth retention.

\section{REFERENCES}

[1] Raj A, Dubey PK, Kumar N, et al. Assessment of prosthodontic status and needs among adult population of Transvaruna Region of Varanasi - a cross sectional study. Journal of Advanced Medical and Dental Sciences Research 2018;6(7):37-40.

[2] Jaleel BF, Nagarajappa R, Mohapatra AK, et al. Risk indicators associated with tooth loss among Indian adults. Oral Health Dent Manag 2014;13(2):170-8.

[3] Nikolovska J, Korunoska-Stevkovska V, Mijoska A, et al. Prosthodontics status and treatment needs among the elderly in the Republic of Macedonia. Open Access Maced J Med Sci 2018;6(5):874-8.

[4] Teofilo LT, Leles CR. Patients' self-perceived impacts and prosthodontic needs at the time and after tooth loss. Braz Dent J 2007;18(2):91-6.

[5] Zhang Q, Witter DJ, Bronkhorst EM, et al. Dental functional status with and without tooth replacement in a Chinese adult population. Clin Oral Investig 2012;16(4):1251-9.

[6] Al-Harbi F, EI Tantawi M. Normative prosthodontic care need: does it impact the daily life of young Saudis with high level of oral diseases? A cross sectional study. BMC Oral Health 2017;17(1):128.

[7] Singh P, Bey A, Gupta ND. Dental health attitude in Indian society. J Int Soc Prev Community Dent 2013;3(2):81-4.

[8] Eachempati P, Shenoy VK, Jain N, et al. Prosthodontic status and needs of elderly institutionalized residents in Mangalore: a prospective study. Indian Journal of Dental Research 2013;24(3):284-8.

[9] Gambhir RS, GuptaT. Need for Oral Health Policy in India. Ann Med Health Sci Res 2016;6(1):50-5.

[10] Sumit K, Kumar S, Saran A, et al. Oral health care delivery systems in India: an overview. International Journal of Basic and Applied Medical Sciences 2013;3(2):171-8.

[11] Bhogisetty C, Rao N, Narayanaraopeta S, et al. Dental prosthetic status and needs of adult rural population living in and around Nalgonda: a survey. Journal of Dr. NTR University of Health Sciences 2012;1(4):245-8.

[12] Oo NSY, Nyan M, Htwe K, et al. A study on association between age, gender and type of removable prosthodontic treatment needs in University of Dental Medicine, Yangon, Myanmar. Myanmar Dental Journal 2016;23(1):1-4.

[13] Peeran SA, Al-Sanabani F, Al-Makramani BM, et al. Dental prosthetic status and treatment needs of adult population in Jizan, Saudi Arabia: a survey report. European Dental Journal 2016;10(4):459-63.

[14] Nadgere J, Gala-Doshi G, Kishore S. An evaluation of prosthetic status and prosthetic need amongst people living in and around Panvel, Navi-Mumbai - a survey. International Journal of Prosthetic Dentistry 2010;1(1):6-9.

[15] Nagaraj E, Mankani N, Madalli P, et al. Socioeconomic factors and complete edentulism in North Karnataka population. J Indian Prosthodont Soc 2014;14(1):24-8.

[16] Hunter JM, Arbona SI. The tooth as a marker of developing world quality of life: a field study in Guatemala. Soc Sci Med 1995;41(9):1217-40. 